\title{
NATRIURESIS OF FASTING IN INTACT AND ADRENALECTOMIZED RATS
}

\author{
Tsutomu NOHNO, Yasuko HAYASHI and Yoshimichi MURAYAMA \\ Department of Pharmacology, Kawasaki Medical School, \\ Kurashiki 701-01, Japan
}

Accepted June 7, 1977

\begin{abstract}
Experiments were carried out in an attempt to elucidate the mechanism of fasting-induced natriuresis in conscious rats. Female animals were given a low sodium diet and saline in a fixed concentration for at least three days, and deprived of food thereafter. The sodium balance significantly shifted to negative independently of potassium supply in intact rats. Such was also observed in the dexamethasonereplaced, adrenalectomized rats and was not affected by further administration of aldosterone. In addition, the diuretic effect of insulin in fasted intact rats was not evident in the fed diabetic rats in which diabetes had been induced by streptozotocin. Such findings suggested participation of factors other than insulin. The natriuresis of fasting in intact rats appears to involve two factors, one of which is independent of the sodium intake level. Dependence on the sodium intake level may be derived from alteration of the solute diuresis-like effect of drinking saline when animals are fasted. These results suggest that neither aldosterone nor insulin is a major causal factor involved in fasting-induced natriuresis.
\end{abstract}

In man and rabbit, many workers have shown that fasting produced natriuresis, and such was arrested by carbohydrate feeding (1-8). Previous reports indicated that in rats also, food deprivation resulted in an increase in sodium excretion or a negative shift of sodium balance. Several hormones regulating the glucose metabolism may be involved in the occurrence of sodium imbalance during the early stage of fasting, however the mechanism remains obscure.

The antidiuretic effect of insulin $(9,10)$ has been attributed to fasting-induced natriuresis and anti-natriuresis by subsequent glucose feeding. In a preliminary report from this laboratory it was confirmed that the negative balance of sodium in fasted rats was not improved but rather enhanced by the administration of insulin (11). Since glucagon has a natriuretic effect in man and the dog (12-14), it is suggested that glucagon may contribute either directly or indirectly to the natriuretic effect of fasting. Moreover, well-known factors, such as aldosterone and antidiuretic hormone, may be implicated in the sodium imbalance.

The present series of studies on the fasting-produced natruiresis was undertaken to determine: (a) The role of sodium and potassium loading in intact fasting rats; (b) the effect of aldosterone in glucocorticoid-replaced adrenalectomized rats; and (c) the effect of insulin in intact or diabetic rats.

\section{MATERIALS AND METHODS}

Female Wistar rats weighing between 190 and $310 \mathrm{~g}$ were maintained on a regular diet 
(CLEA CE-2) containing $126 \mathrm{mEq} \mathrm{Na}$ and $221 \mathrm{mEq} \mathrm{K}$ per $\mathrm{kg}$ and tap water was provided ad libitum before experiments. Each group included nine rats for each experiment unless otherwise indicated.

Equilibration studies were carried out for a minimum 3 days before the start of fasting. During this period the animals were placed separately in siliconized metabolism cages (CLEA CT-10), and given NaCl solution in fixed concentration $(15,40,77$ or $120 \mathrm{mM})$ and a low sodium diet. The latter was produced in our laboratory according to the components of the CLEA low sodium diet (Mixture No. 66), containing $2.9 \mathrm{mEq} \mathrm{Na}$ and $125 \mathrm{mEq} \mathrm{K}$ per $\mathrm{kg}$, which consisted of dried powder composed of sucrose $(65 \%)$, vitamin-free casein $(20 \%)$, vegetable oil $(5 \%)$, cellulose $(6 \%)$, inorganic salts $(4 \%)$ and vitamins (Vitamin Mix for CLEA CE-2 diet).

After completing the equilibration studies, the low sodium diet was withdrawn at 9 a.m., then the rats were fasted for 5 days. The experiments were carried out at a room temperature at $22 \pm 2{ }^{\circ} \mathrm{C}$ and a light cycle of on at 6 a.m. and off at 6 p.m. When determining the effects of potassium on sodium balance, mineral water and a sodium- and potassium-deficient diet was provided in place of the $\mathrm{NaCl}$ solution and the low sodium diet. Mineral water consisted of $15 \mathrm{mM} \mathrm{NaCl}$ and $30 \mathrm{mM} \mathrm{KCl}$, and the food had a composition similar to the low sodium diet except for the non-inclusion of inorganic salts.

To determine the effect of adrenocortical hormones on sodium balance, adrenalectomy was carried out 4 to 7 days before the start of the equilibration studies mentioned above. For 4 to 6 days before the start of the fast, dexamethasone (Nippon Merck-Banyu) either alone or concomitantly with aldosterone (CIBA-Geigy) was administered s.c. in $10 \% \mathrm{~g}$ and $5 \mathrm{gg} / 100 \mathrm{~g}$ B.W. a day, respectively.

Renal effects of exogenous insulin in insulin-deficient rats were determined as follows. Experimental diabetes was induced by an i.p. injection of $7.5 \mathrm{mg} / 100 \mathrm{~g} \mathrm{~B}$.W. of streptozotocin (Upjohn) solution in $0.01 \mathrm{M}$ citrate buffer $(\mathrm{pH} \mathrm{5.5)}$. The criterion for the development of experimental diabetes was that the concentration of non-fasting plasma glucose was in excess of $200 \mathrm{mg} / 100 \mathrm{ml} 5$ days after the administration. Daily injection of lente insulin (Shimizu) was begun on day 32 after administration of streptozotocin. Insulin was injected s.c. in $4 \mathrm{U} / 100 \mathrm{~g} \mathrm{B.W}$. at $9 \mathrm{a} . \mathrm{m}$. and in $12 \mathrm{U} / 100 \mathrm{~g} \mathrm{B.W}$. at $5 \mathrm{p} . \mathrm{m}$. while at the same time providing the rats with a regular dict. Glucose concentration in tail vein blood was measured once every other day.

Hematological and chemical analyses of blood constituents were performed in rats fed a regular diet. Blood was taken from the cervical vessels following decapitation between 2 p.m. and 5 p.m.

In the metabolic experiments, body weight, food and fluid intake, urine volume and osmolality, and urinary sodium and potassium output were measured daily. The sodium and potassium concentration was determined using a Hitachi flame photometer (Model 205), and urine osmolality was measured by the freezing point depression with a Fiske osmometer (Model 230D). For determination of hematocrit values, heparinized microhematocrit tubes were used. Serum was kept at 20 C for further assays. Serum or plasma glucose 
and urea concentrations were determined using the Glucose Test kit (Wako) and Urea $\mathrm{N}$-Test kit (Wako), respectively. Total serum protein was determined by the ultraviolet absorption method of Murphy and Kies (15). Student's t-test was used to determine the statistical significance.

\section{RESULTS}

\section{Sodium excretion in fasted rats}

When a regular diet was replaced by a low sodium diet, the urinary excretion of sodium decreased, as shown in Fig. 1. The rate of decline was, however, slower during total fasting than during simple sodium deprivation, implying that fasting can induce a natriuresis.

\section{Effects of sodium intake and fasting on the sodium and water balance}

When food was withdrawn after 3 days on a low sodium diet and drinking water containing 15,40 or $120 \mathrm{mM} \mathrm{NaCl}$, the balance (intake minus output) of sodium shifted to negative (Fig. 2 and Table 1). In this experiment, rats had access to the saline solution ad libitum, but the intake of water decreased to nearly the same extent in all groups during the first 3 days of fasting. Therefore, the higher the saline concentration, the greater was the reduction of sodium intake. A quicker negative shift of sodium balance observed in

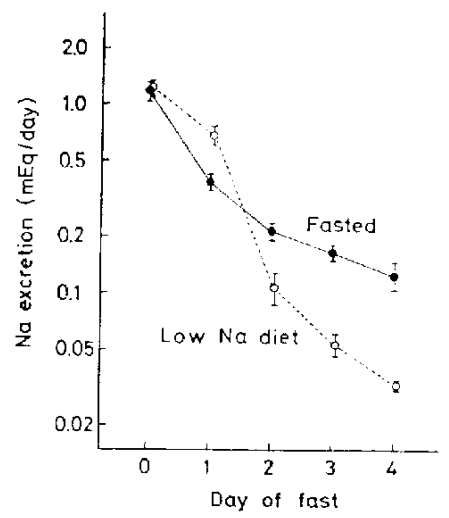

Fig. 1. Comparison of diminution curves of sodium excretions in fed and fasted intact rats provided demineralized water for drinking. A regular dier was withheld $(\bigcirc)$ or replaced with a low sodium diet () on day 0 . Values are presented in means $t$ standard errors of 6 rats.

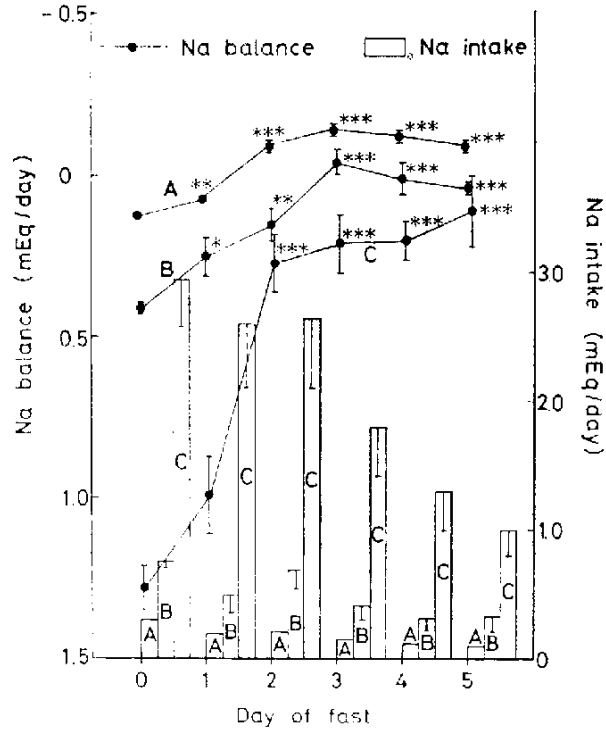

FIG. 2. Changes in sodium balance and intake during fasting in intact rats provided saline solution of which $\mathrm{NaCl}$ concentrations were as follows: $\mathrm{A}, 15 \mathrm{mM} ; \mathrm{B}$, $40 \mathrm{mM}: \mathrm{C}, 120 \mathrm{mM}$. Day 0 represents the last day of equilibration period. Means \pm standard errors of 45 (A) or 9 (B, C) rats. Statistical significance vs. prefast day: *, $\mathrm{p}<0.05$ * $^{* *}, \mathrm{p}<0.01$; $^{* * *}$, $\mathrm{p}<0.001$. 


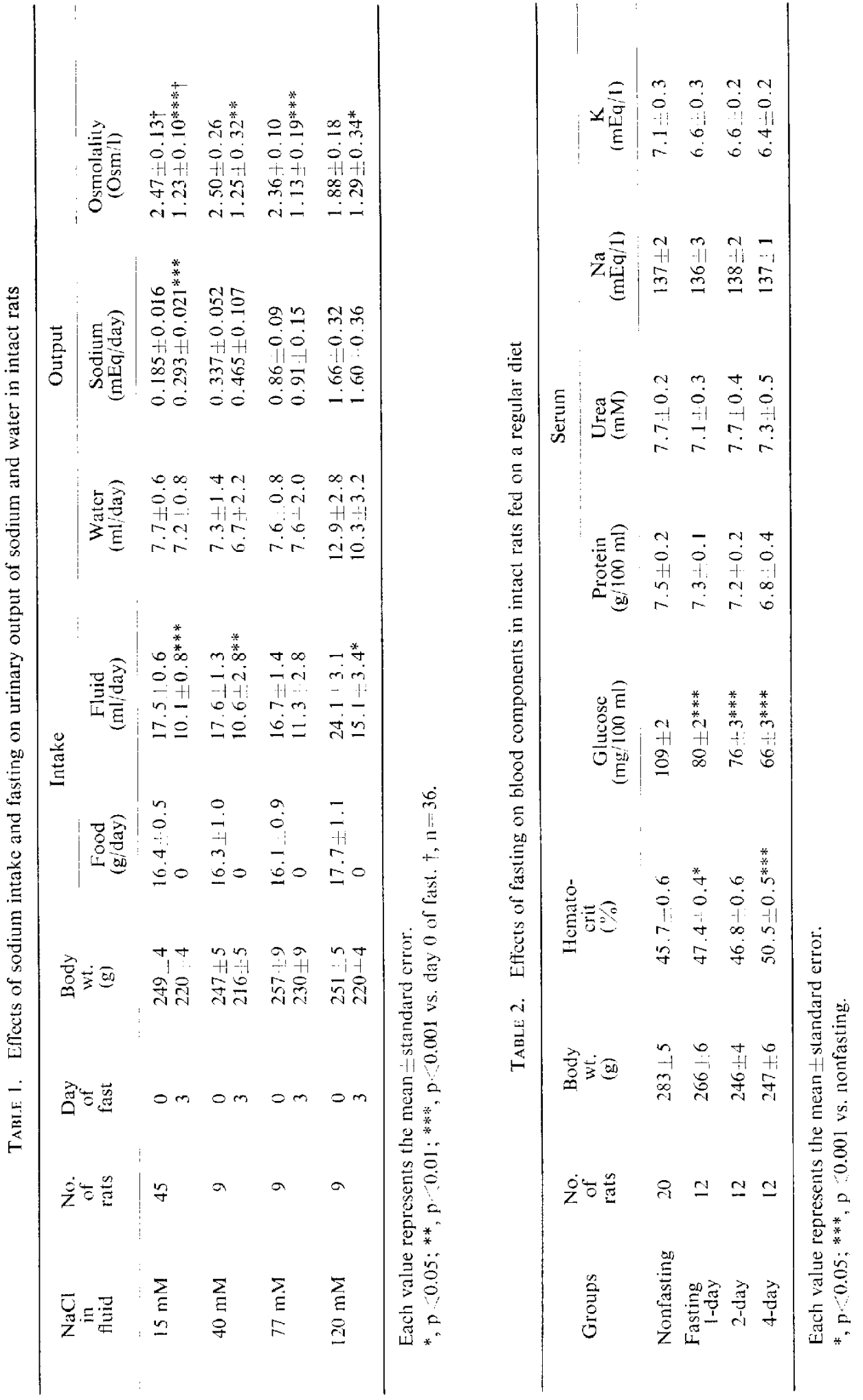




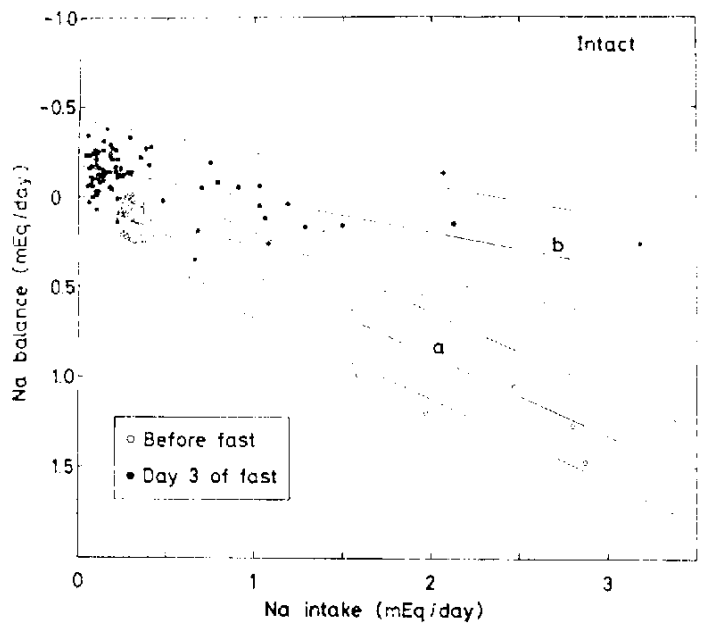

FrG. 3. Sodium balance as a function of sodium intake in intact rats. Sodium balance was plotted against sodium intake in individual animals. Linear relationship is expressed as the following equations: line $a$ (before fast), $\mathrm{Y}=-0.007-0.445 \mathrm{X}$ $(\mathrm{r}=0.943, \mathrm{p}<0.001)$; line $b$ (day 3 of fast), $\mathrm{Y}--0.174-10.186 \mathrm{X}(\mathrm{r}=0.722, \mathrm{p}<$ 0.001 ). Broken lines represent the $95 \%$ confidence limits of regression lines for a single measurement.

the first few days (Hig. 2) may be due to the evident decrease in sodium intake. Howcver, an increase in sodium excretion persisted until at least day 5 of fasting in the rats ingesting low sodium water, while the output of water remained constant. These observations indicate that natriuresis may occur with fasting despite a remarkable reduction in fluid intake.

The values of sodium balance in 78 rats were plotted against the sodium intake both on the prefast day and on day 3 of the fast (Fig. 3). Linear relationships existed between sodium balance and its intake, and their regression equations were $Y=-0.007-0.445 \mathrm{X}$ $(\mathrm{r}-0.943)$ for the prefast day (line $a)$ and $\mathrm{Y}=-0.174 \mid 0.186 \times(\mathrm{r}=0.722)$ for on day 3 of fast (line $b$ ), respectively. It is readily perceived that the negative shift of sodiun balance as the result of fasting was greater in the rats ingesting a greater amount of sodium.

In addition to hematocrit values, plasma glucose, protein, urea, sodium and potassium were determined in non-fasted and fasted rats (Table 2). One to four days after food deprivation, the serum glucose concentration decreased significantly, while the hematocrit increased. No significant changes were notcd in the other constituents.

\section{Effects of potassium intake and fasting on the sodium and water balance}

Rats were fed a sodium- and potassium-deficient diet and mineral water containing $15 \mathrm{mM} \mathrm{NaCl}$ and $30 \mathrm{mM} \mathrm{KCl}$ for 3 days. All food was witheld and the animals were allowed free access to mineral water. A negative shift in the sodium balance was achieved in a pattern similar to curve $A$ in Fig. 2 with the maximum shift on day 4 of the fast $(-0.062$ $\perp 0.022 \mathrm{mEq} /$ day as compared with $0.051 .0 .016 \mathrm{mEq} /$ day in control, $\mathrm{p}<0.001$ ). Potassium balance also shifted to the negative ( $0.197: 0.077 \mathrm{mFq}$ day as compared with 0.138 $+0.025 \mathrm{mEq}$ /day in control, $\mathrm{p}<0.001$ ). In addition, the absolute increase in sodium and 
potassium excretion was cvident between 2 to 4 fasting days despite a fall in fluid intake to half that in control period.

Effect of adrenalectomy on the natriuresis of fasting

When adrenalectomized rats were given a low sodium diet and 40 or $77 \mathrm{mM}$ saline solution as drinking water, the sodiun intake varied with the water intake. Fig. 4 shows

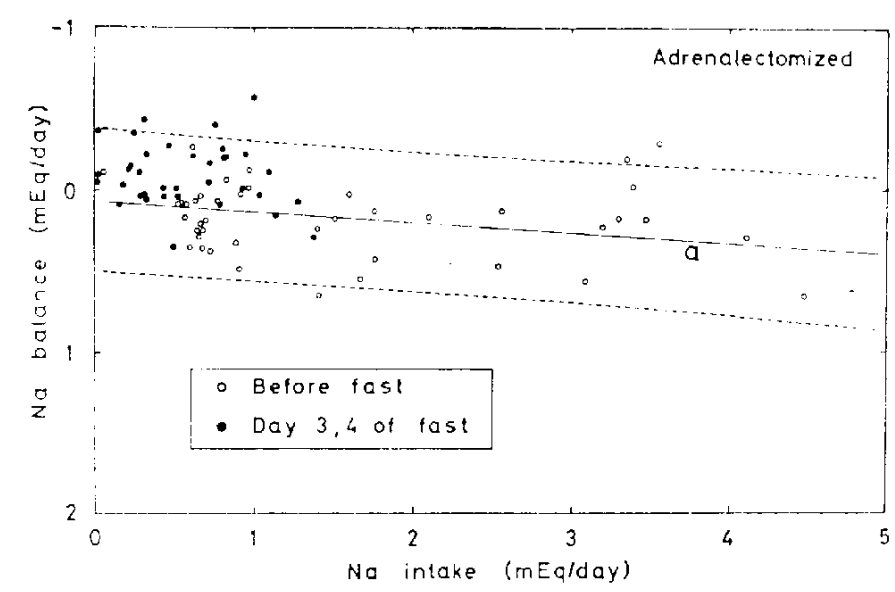

Fig. 4. Sodium balance as a function of sodium intake in adrenalectomized rats. Linear relationship is expressed as the following equation: line a (before fast), $Y=0.065+0.064 X(r=0.405, p, 0.05)$. Others are the same as in Fig. 3.

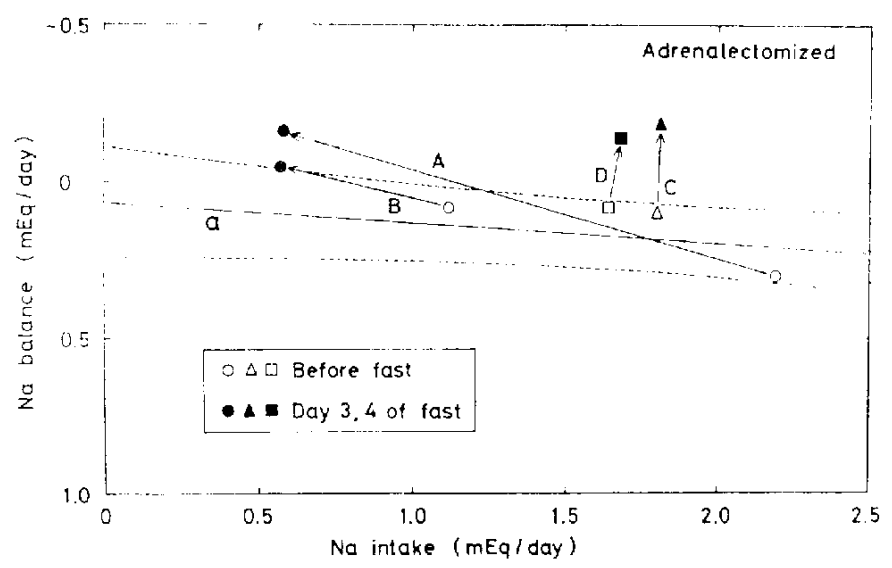

FiG. 5. Fasting-induced shift of sodium balance in adrenalectomized rats with or without replacement by exogenous corticosteroids. $\mathrm{NaCl}$ solution was provided throughout the experiments in $77 \mathrm{mM}$ except for $\mathrm{B}$ in $40 \mathrm{mM}$ before fast and in $80 \mathrm{mM}$ during fasting. $\mathrm{A}$ and $\mathrm{B}$, without hormonal replacement; $\mathrm{C}$, daily administration of dexamethasone alone (10) $4 \mathrm{~g} / 100 \mathrm{~g}$ B.W.); D, daily administration of both dexamethasone $(10 / \mathrm{g} / 100 \mathrm{~g}$ B.W. $)$ and aldosterone $(5 / \mathrm{g} / 100 \mathrm{~g} \mathrm{B.W}$. $)$. Data are presented in mean values of 9 rats on the prefast day and on days 3 and 4 of fast. Statistical significance in sodium balance: $\Lambda, p-0.01 ; B, p<0.05$ : C, p, $0.1 ; D, p-0.05$. Broken lines represent the $99 \%$ confidence limits for the regression line $a$ cited from Fig. 4 


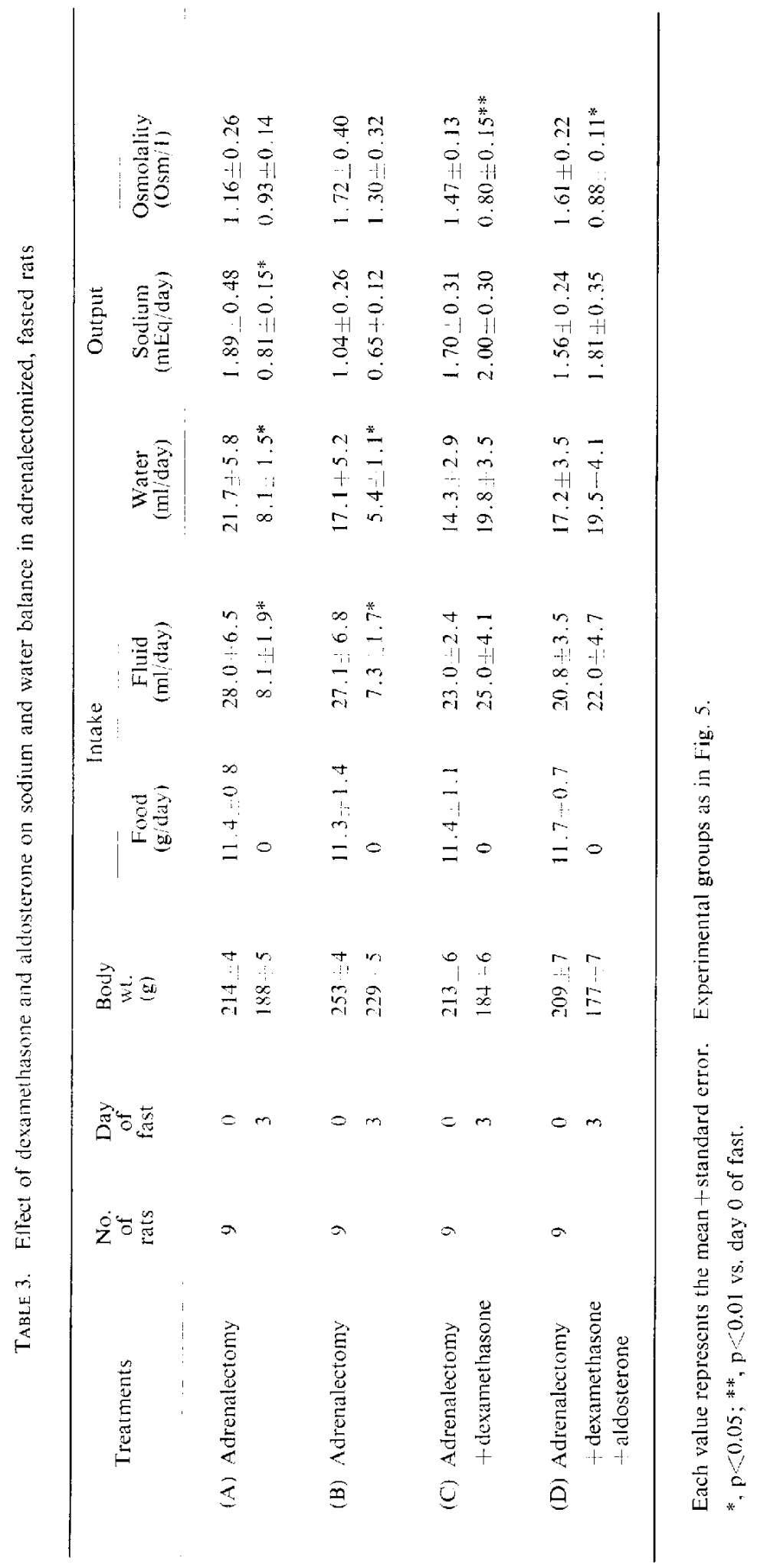


the relationship between sodium balance and sodium intake on the prefast day and on days 3 and 4 of the fast in adrenalcetomized rats. The regression equation on the prefast day was $Y .0 .065-10.064 X(r=0.405)$, which is indicated by line $a$ in Fig. 4. However, on days 3 and 4 of the fast, the relationship was equivocal (closed circles in Fig. 4).

Following food deprivation for 3 or 4 days with free access to $77 \mathrm{mM}$ saline solution, the sodiun intake was markedly reduced from $2.19: 0.50 \mathrm{mEq} /$ day to $0.58: 0.09 \mathrm{mEq} / \mathrm{day}$, and the sodium balance shifted from $0.30 \pm 0.07 \mathrm{mEq} /$ day to $-0.16-0.05 \mathrm{mEq} / \mathrm{day}(\mathrm{p}<0.01$, $A$ in Fig. 5), while no significant changes of the sodium intake and balance were observed in the non-fasted adrenalectomized control rats.

When the concentration of saline solution was reduced to $40 \mathrm{mM}$, sodium intake was decreased on the prefast day $(1.12 \perp 0.27 \mathrm{mEq} /$ day, B in Fig. 5). If the saline solution was changed to $80 \mathrm{mM}$ during the fast, the sodium intake decreased to $0.57 \pm 0.09 \mathrm{mEq} /$ day and such was accompanied by a negative shift in sodium balance $(0.08 \pm 0.04$ to $-0.05 \ldots 0.03$ $\mathrm{mEq} /$ day, $\mathrm{p}<0.05$ ), as indicated as $\mathrm{B}$ in Fig. 5 . These results suggest that the decrease in saline intake has to be considered when investigating sodium balance.

However, if dexamethasone was given to the adrenalectomized rats ingesting $77 \mathrm{mM}$ $\mathrm{NaCl}$ solution as drinking water, the sodium intake remained unchanged, but the sodium balance shifted to the negative (from $0.10: 0.17$ to $-0.18 \div-0.06 \mathrm{mEq} / \mathrm{day}, \mathrm{p}>0.1, \mathrm{C}$ in Fig. 5). When aldosterone and dexamethasone were given concomitantly, the negative shift of sodium balance occurred with no decrease in sodium intake (from $0.08+0.07$ to 0.14. $0.05 \mathrm{mEq} /$ day, $\mathrm{r} .0 .05$, D in Fig. 5). The overall results in adrenalectomized rats are shown in Table 3. Without dexamethasone treatment, urine flow was decreased to one-third after 3 days of fasting, but urine osmolality was not significantly reduced. On the contrary, in dexamethasone-treated rats, urine flow increased while urine osmolality was significantly decreased. In addition, daily intake of food in the adrenalectomized rats was reduced to about $70 \%$ as compared with intact rats.

Renal cffects of insulin crecess or deficicncy

In a preliminary paper (11), we reported that the natriuresis of fasting was inhibited by carbohydrate refeeding in rats, as is the case with man (3-6). The results are as follow's (sce Fig. 6): The negative shift of sodium balance in fasted rats was suppressed by sucrose refeeding, but was not affected by a lower dose $(0.02 \mathrm{U} /$ day) of insulin s.c.; by a higher dose ( $0.2 \mathrm{U} / \mathrm{day})$, however, the negative shift was enhanced. If insulin per se indeed has a sodiumretaining effect $(9,10)$, those results are contradictory. To elucidate this point, further investigation was carried out, in which insulin-deficient rats $(n=7)$ were given insulin s.c. while fed a regular diet. On day 32 after streptozotocin injection, daily administration of lente insulin s.c. was begun in a dose of $16 \mathrm{U} / 100 \mathrm{~g} \mathrm{B.W}$. per day. Plasma glucose concentration was $540-15 \mathrm{mg} / 100 \mathrm{ml}$ on the pretreatment day, but was decreased to $91+10 \mathrm{mg}$; $100 \mathrm{ml}$ on day 2 , then, to $41 \pm 4 \mathrm{mg} / 100 \mathrm{ml}$ on day 4 of insulin therapy. As shown in Fig. 7, urinary excretion of sodiun and potassium immediately decreased on days 1 and 2 of insulin administration, after which a return to the initial levels was noted. Urine flow remained at the significantly decreased level throughout insulin therapy, whereas urine osmolality 

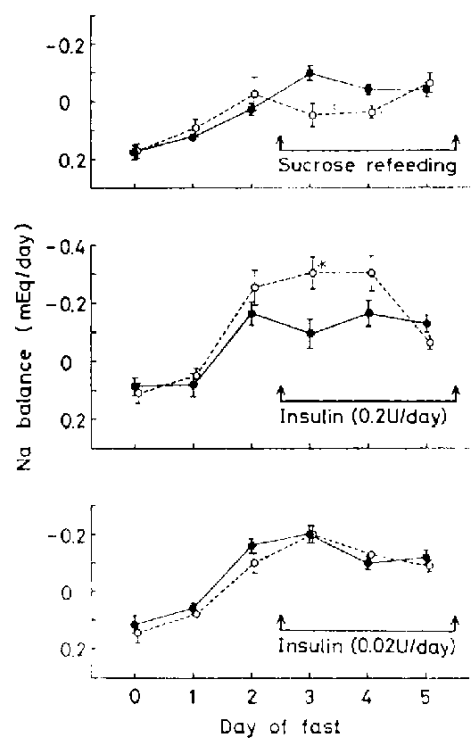

FIG. 6. Effects of sucrose refeeding and insulin injection on negative sodium balance in fasted intact rats. After a 2-day fast, experimental groups (O) were given sucrose p.o. or insulin s.c. $(0.02$ or 0.2 $\mathrm{U} / 100 \mathrm{~g} \mathrm{B.W.}$.) daily, while control groups (O) were kept fasting. Means $\$$ standard crrors of 9 rats. Statistical significance vs. control group: *, $\mathrm{p}<0.05 ;{ }^{* *}, \mathrm{p}<0.01$
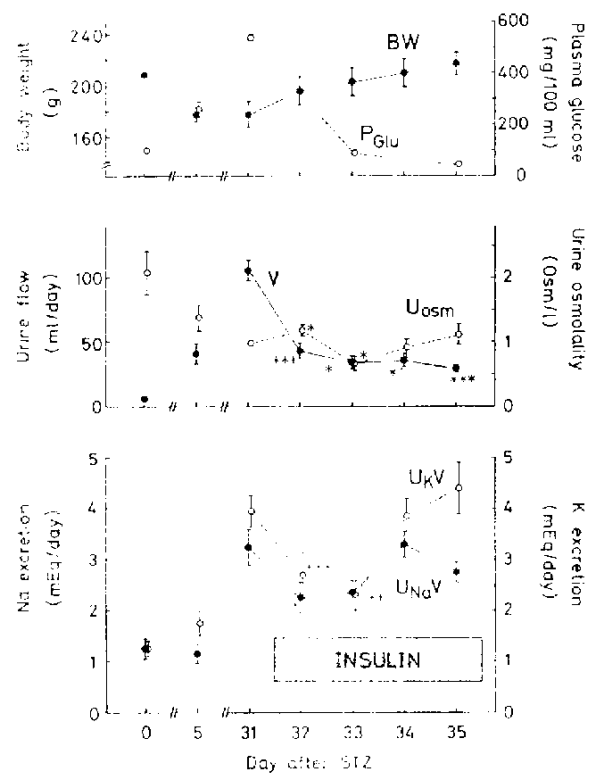

Fig. 7. Renal effects of exogenous insulin in fed diabetic rats as induced by streptozotocin. Streptozotocin (STZ) was injected i.p. in a dose of $7.5 \mathrm{mg} / 100 \mathrm{~g}$ B.W. on day 0 , and insulin therapy was bcgun on day 32 thereafter in a dose of 16 U/100 g B.W. per day. Metabolic activity of exogenous insulin was followed by measuring plasma glucose. Values are presented in means I standard errors of 7 rats. Statistical significance vs. pretreatment day of insulin (day 31): *, $\mathrm{p}<0.05 ;{ }^{* *}, \mathrm{p}<0.01 ; * * *, \mathrm{p}<0.001$.

was raised on day $\mathbf{I}$ and lowered on day 2. Thus a discrepancy exists between diabetic rats and fasted non-adrenalectomized rats regarding the renal effects of insulin.

\section{DISCUSSION}

The results of the present study on the pattern of sodium excretion at the early stage of fasting in conscious rats are compatible with those obtained in man (1-7). Fasting induced a natriuresis which was independent of potassium supply, and as far as the constant potassium intake was maintained, kariuresis was also induced by fasting. When a normal level of sodium intake ( $1.68 \mathrm{mEq} /$ day) was maintained, rats ingesting a low sodium diet and saline solution showed more positive values of sodium balance $(0.74 \mathrm{mEq} /$ day from the line $a$ in Fig. 3) than did animals on a regular diet and water $(0.21 \mathrm{mEg} /$ day $)$. The higher the concentration of $\mathrm{NaCl}$ in the drinking water, the greater was the sodium output (Table 1), thus the ingestion of saline leads to the diuretic response.

Owing to the water loss with such a diuresis, the rats had to ingest more water. As a result, much sodium could be retained despite the diuretic response in fed intact rats ingesting 
saline solution. When these rats were fasted, the abnormal sodium retention appeared to be overcome, as indicated in the decrease in a slope of regression line in Fig. 3. The kidney of rats during fasting may respond to the sodium load more readily than otherwise. This was clearly demonstrated in the previous experiments using the method of i.v. infusion of hypertonic saline in anesthetized rats (16), but the mechanism remains obscure.

The theoretical values of sodium balance when sodium intake is zero (as extrapolated from the regression lines in Fig. 3) are $-0.007 \mathrm{mEq} /$ day in non-fasting rats and $-0.174 \mathrm{mEq} /$ day in fasting for 3 days, respectively. Such a difference cannot be explained by the difference in sodium intake. Therefore, the negative shift of sodium balance during fasting with the lower level of sodium intake may be regulated by other factor(s), as discussed below.

Water balance (fuid intake minus urinary output) was consistently lowered from about $10103 \mathrm{ml}$ /day under the supply of 15,40 and $77 \mathrm{mM} \mathrm{NaCl}$ on day 3 of fast in intact rats (Table 1). This may be interpreted in terms of the contraction in extracellular fluid volume, which was reflected in the increase in hematocrit (Table 2) and in the negative shift of sodium balance during fasting ( $\Gamma$ ig. 2). On the other hand, urine osmolality was also reduced on day 3 of the fast. Since the homatocrit was increased during fasting, this should not be ascribed to a lowered secretion of antidiuretic hormone (17). Moreover, the renal responsiveness to antidiuretic hormone was not significantly altered on day 2 of fast in conscious rats (unpublished data). Therefore, it is unlikely that the reduction in urine osmolality by fasting is principally derived from the lowered renal response to antidiurctic hormone. An alternative explanation is that corticomedullary osmotic gradient may decline with the lowered sodium reabsorption in the thick ascending limb of Henle's loop and with the decreased urea trapping in medulla (18).

Several inconsistent results have been presented with respect to the change in aldosterone excretion or secretion rate during fasting and subsequent carbohydrate refeeding $(2,4,19$

22). Boulter et al. reported that the aldosterone secretion rate rose early in the fast even though constant sodium and potassium intake was maintained (22). Spark et al. postulated that this discrepancy might arise from the fall of renal responsiveness to mineralocorticoid under the influence of glucagon (23). We therefore used adrenalectomized rats to determine whether or not the fasting-induced natriuresis did in fact implicate aldosterone. The negative shift of sodium balance due to fasting was almost equivalent between aldosteronedeficient rats and aldosterone- and dexamethasone-replaced adrenalectomized rats ( $\mathrm{C}$ and $\mathrm{D}$ in Fig. 5). With aldosterone administration, absolute excretion of sodium was somewhat decreased (Table 3), but was accompanied by an apparent kariuresis, indicating that the exogenous aldosterone employed herein, despite the half-maximum dose of secretion rate in rats (24), was as effective as ondogenous aldosterone. From these results, it may be concluded that mineralocorticoid is not involved in the fasting-induced sodium imbalance, at least, as an essential factor. However, the sodium balance was not significantly different in both calses during feeding states, but about the same ( $C$ and $D$, open symbols in Fig. 5). This result of sodium balance may be attributed to the "escaped response" of the kidney to aldosterone $(25,26)$. 
While ingesting food, urinary excretion of sodium and water in hypoadrenal states was much greater than that in normoadrenal states when $\mathrm{NaCl}$ solution in the same concentration ( 40 or $77 \mathrm{mM}$ ) was given as drinking water (Tables 1 and 3). On the contrary, during fasting, the diuretic response disappeared in adrenalectomized rats, and the pattern of urinary excretion was similar to that in intact rats on day 3 of fast (Tables 1 and 3). This implies that adrenal function was impaired during fasting in intact rats. Furthermore, dexamethasone-induced diuresis was cvident only in fasted adrenalectomized rats (A and $\mathrm{C}$ in Table 3). Further experiments are requircd for elucidation.

As shown in Fig. 6, administration of insulin s.c. gave rise to the natriuretic response of the kidney in fasted intact rats. On the other hand, insulin therapy caused a decrease in excretion of sodium and water with the elevation of urine osmolality in diabetes mellitus rats during feeding (Fig. 7). In addition, diuretic and natriuretic effects of a physiologic dose of insulin (i.v.) were not observed in our clearance experiments with fasted intact rats (unpublished data), and such findings are compatible with reports in humans and dogs $(9$, 10). Therefore, the apparent natriuretic effect of insulin in intact rats (Fig. 6) has to be explained in terms of association of factor(s) other than insulin. For the decrease in excretion of sodium and water on days 1 and 2 of insulin therapy in diabetic rats, two factors may be responsible: (a) Disappearance of the solute diuresis-like effect of hyperglycemia with insulin therapy; (b) reduction of the natriuresis induced by glucagon (12-14) due to the restoration of insulin-deficient hyperglucagonemia by exogenous insulin $(27,28)$. Likewise, glucagon as a possible factor may contribute not only to the diuretic, natriuretic response caused by s.c. administration of insulin in intact rats, but also to the fasting-induced natriuresis and its recovery by sucrose refeeding. It has been reported that glucagon enhanced the urinary excretion of sodium and water (12-14), and when we infused glucagon into the renal artery in non-fasted rats a similar effect was noted (unpublished data). It was also reported that the plasma concentration of glucagon increased early in the fast (14, 29,30). These findings suggest that glucagon may play an important role in fasting-induced natriuresis.

Acknowledgements: The authors wish to thank Prof. T. Saito of our laboratory for critical reading of the manuscript and A. Segawa for technical assistance.

\section{RFFERENCES}

1) Stinfhalkih, B.J. and Schloeder, F.X.: Mélabolism 15, 828 (1966)

2) Chinn, R.H., Brown, J.J., Frastr, R., Heron, S.M., Levir, A.F., Murchison, L. and Rohertson, J.I.S.: Clin. Sci. 39, 437 (1970)

3) Splenche, H., I.Fwin, I., Samachson, J. and Laszlo, J.: Am. J. Med. 40, 27 (1966)

4) Katy, A.l., Holdivgsworth, D.R. and Erstrin, F.H.: J. Lab. clih. Med. 72, 93 (1968)

5) Kolanovski, J., Pizarro, M. A., de Gasparo, M., Desmecht, P., Harvengt, C. and Crabdí, 1. : Europ. J. clin. Invest. 1, 25 (1970)

6) Boultik, P.R., Hoffmav, R.S. And Arky, R.A.: Metabolism 22, 675 (1973)

7) Sigler, M.H.: I. clin. Inle'st. 55, 377 (1975)

8) CIzEK, L.J.: Am. J. Physiol. 201, 557 (1961)

9) Nizet, A., Leflibre, P. And Crabeí, J.: Pflügers Arch. 323, 11 (1971)

10) DeFronzo, R.A., Goldberg, M. ANd Agus, Z.S.: J. clin. Invest. 58, 83 (1976) 
11) Hayasht, Y., Nohno, T. and Murayama, Y.: Japan. J. Pharmacol. 26, 627 (1976)

12) Pullman, T.N., Lavender, A.R. And Aho, I.: Metabolism 16, 358 (1967)

13) LevY, M. And STARK, N.L.: Kidney Int. 2, 76 (1972)

14) Saudek, C.D., Boulter, P.R. ANd Arky, R.A.: J. clin. Endocr. Metab. 36, 761 (1973)

15) Murphy, J.B. And Kies, M.W.: Biochim. Biophy.s. Acta 45, 382 (1960)

16) Murayama, Y., Watanabe, S. And Hayashl, Y.: Folia pharmacol. japon. 72, 229 (1976) (in Japanese)

17) Duni, F.t., Brennan, T.J., Nleson, A.E. and Robertson, G.L.: J. clin. Invest. 52, 3212 (1973)

18) Murayama, Y. and Sakal, F.: Japan. J. Pharmacol. 25, 475 (1975)

19) Rapoport, A., From, G.L.A. And Husdan, H.: Metabolism 14, 31 (1965)

20) Haag, B.L., Reidenberg, M.M., Shuman, C.R. and Channick, B.J.: Am. J. med. Sci. 254, $652(1967)$

21) Garnett, E.S., CoheN, H., Hallmias, C. and VIol, G. : Metabolism 22, 867 (1973)

22) Boulter, P.R., Spark, R.F. And Arky, R.A.: J. clin. Endocr. Metab. 38, 248 (1974)

23) Sirakk, R.F., Arky, R.A., Boulter, P.R., Saudek, C.D. and O'brian, J.T.: New Engl. J. Med. 292, 1335 (1975)

24) Cade, R. and Perenich, T.: Am. J. Physiol. 208, 1026 (1965)

25) Wright, F.S., Knox, F.G. Howards, S.S. and Beru.jner, R.W.: Am. J. Physiol. 216, 869 (1969)

26) KNochel, J.P. AND White, M.G.: Arch. int. Med. 131, 876 (1973)

27) Müller, W.A., Faloona, G.R. and Unger, R.H.: J. clin. Invest. 50, 1992 (1971)

28) Buchanan, K.D. and Mawhinney, W.A.A.: Diabetes 22, 797 (1973)

29) Aguil.ar-Parada, E., Eisentraut, A.M. and Unger, R.H.: Diabetes 18, 717 (1969)

30) Marliss, E.B., Aokı, T.T., Unger, R.H., Soeldner, J.S. and Cahlll, G.F., Jr.: J. clin. Invest. 49, $2256(1970)$ 